\title{
Research on the Teaching Design of the Flipped Classroom Based on the Automobile Insurance Claim
}

\author{
Ying Han * \\ Qingdao Binghai University \\ Qingdao, Shandong province, China 266555 \\ hanying0926@163.com
}

\author{
Yanyan Shi \\ Qingdao Binghai University \\ Qingdao, Shandong province, China 266555 \\ 471618585@qq.com
}

\begin{abstract}
It has aroused peoples' attention for the flipped classroom as a new teaching mode. This teaching mode can optimize the teaching activity and promote the passing on the knowledge. In this paper, the teaching mode of the flipped classroom is tried to study aim at the Automobile Insurance claim course in the vocational colleges, and Classroom teaching design is also studied. Base on analysis of the flipped classroom meaning and characteristics, it has been presented for a set of classroom teaching design of flipped classroom suiting the student of vocational colleges.
\end{abstract}

Keywords-Flipped classroom; Micro-lesson video; Teaching design; Teaching reflection

\section{INTRODUCTION}

In recent years, the teaching method of flipped Classroom is very popular at home and abroad. A lot of successful cases have been sprung up from the basic education to higher education. In foreign countries, it has obtained the very good evaluation that the flipped classroom was used on the "microeconomics" curriculum in the University of Miami [1]. The flipped classroom teaching of "introduction to statistical" courses were studied by strayer (2007) [2], and the flipped classroom teaching of "Linear Algebra" courses were also studied by Talbert (2011)[3]. Since 2010, the study is more and more get the attention of the education workers for the flipped classroom. But in china it is a little lag. In 2011, the sallman Khan made a speech of "use Video to create education" on TED, and the Flipped classroom concept was introduced to China. Then the flipped classroom has attracted the attention highly. Jian-li Jiao (2012) introduced to the concept of the Flipped classroom by the way of connotation explanation. The origin and implementation step and practical case of flipped classroom were analyzed deeply by Zhang Jinlei et. Chen Zhenguo analyzes the application of the flipped classroom in various schools and curriculums [4]. The various theories and The use of effective methods of Flipped classroom were explored by Yan-ling jiang(2014). There are many scholars to analyze and practice the flipped classroom [5].

At present, the research on the flipped classroom was carried out from theory to practice at many angles. However, in the vocational colleges, the research of the flipped classroom application is less. How to carry out the corresponding teaching method also did not see a specific operational. This paper is based on the status quo; a set of flipped classroom teaching design in higher vocational college is putted forward by the teaching practice of Automobile Insurance claim course.

\section{CONNOTATION OF THE FLIPPED CLASSROOM}

FCM is short for "Flipped Class Model", it is usually translated into "flipped class", "reversed class" or "inverted classroom”, or called "flipped classroom teaching mode”. Its basic idea is: turning the traditional learning process upside down, let learners complete the self-study of the knowledge and concepts in spare time, so that the class becomes a place of interaction between teachers and students, and is mainly used to answer doubts, discuss reports, so as to achieve better teaching results [6].

\section{A. Flipped classroom needing the flexible teaching environment}

Flipped classroom teaching model has changed the graffitistyle teaching of teachers in traditional teaching model, it can adopt a variety of teaching modes, including group work, independent thinking, speech, answer, etc. Flipped classroom is a teaching model in which teachers record the relevant knowledge through recording micro-lesson videos in advance and distribute them to students to learn before classroom. This flexible learning environment can facilitate students' selflearning at home, in school, or on the way to classroom. Teachers' methods of evaluating students also use flexible forms, including preview and inspection before class, live scoring in class, student peer assessment and other forms, so that can objectively evaluate students' learning.

\section{B. Flipped classroom needing to elaborately record micro- lesson video}

Flipped classroom teaching mode requires students to study before class by learning micro-lesson videos recorded by teachers, so teachers' micro-lesson videos play a vital role in students' learning. Micro-lesson videos should be short and pithy, usually 5-10 minutes, teachers need to extract the important points of this lesson, explain the main points clearly in plain language. 


\section{Flipped class needing to plan the class design elaborately}

Rich and effective class design is an important part of students' knowledge-internalization, in class students can digest the issues accumulated in the learning before class, and teachers need to consider what should be taught by using teaching method, what should be learned by students themselves and what should be discussed in class. Using welldesigned teaching content can maximize the use of class time, therefore, according to different disciplines and different characteristics of learners adopt a variety of teaching methods, integrated design each section of "flipped classroom."

\section{Flipped classroom needing a complete evaluation system}

The study consciousness of students in higher vocational college is poor. Effective evaluation system can stimulate students' motivation to learn, and plays a crucial role in the smooth implementation of the idea of flipped class. Evaluation content includes micro-lesson video learning situation before classroom, the participation of class design, etc.

\section{FEASIBILITY ANALYSIS OF THE COURSE OF AUTOMOBILE INSURANCE CLAIMS COURSE IN THE FLIPPED CLASSROOM.}

Whatever the course, and the theory and practice, in the flipped classroom instruction to find out whether there is a possibility. The key to measuring the feasibility of flipped classroom lies in the combination of curriculum and flipped teaching mode. Correspondence refers to the course training objectives, characteristics can be maximized through the flipped classroom model[7]. Automobile insurance claims the objectives of the curriculum is enable students to become familiar with the auto insurance business and law, have a good estimation of the vehicle repair costs, understand auto parts price and the ability of the motor vehicle valuation, with analysis of specific cases of processing capacity. Flipped classroom teaching mode is can enable students to learn microlesson video before classroom. In class for the relevant case between students and teachers to analyze and communicate with each other, ensure the professional knowledge and practice in the classroom to complete seamless.

\section{TEACHING DESIGN OF THE COURSE OF THE FLIPPED} CLASSROOM IN AUTOMOBILE INSURANCE AND COMPENSATION.

The automobile insurance, the course content of this chapter as the flipped classroom teaching design , the content of this chapter in the whole semester teaching time have eight hours, plays an important role in the whole knowledge is basis of learning this course. The flipped classroom use before class micro-lesson learning "motor vehicle third party liability insurance", the insurance liability, liability exemption, insurance amount and compensation processing etc. content, in the micro lesson video interspersed with some questions, and finally analysis of the specific case. Students in the classroom before the micro class learning, deepen the understanding of the content of the students. Establish a discussion group; discuss the specific cases in class, and processing the results of the case. Through this series of learning and discussion, it can enhance the students' ability to apply the knowledge and improve the students' learning interest and the active classroom learning atmosphere.

Emphasis on Curriculum: understanding of the exemption of liability and its application in case analysis. Course difficulty: the understanding of the relevant regulations of the insurance and the use of the Ordinance to carry out a case analysis.

\section{A. Learner characteristics analysis}

The teaching object is the students of Higher Vocational College, the foundation is poor, and the consciousness of the study is low. Under the current traditional teaching methods, it is difficult to improve the majority of students' learning interest in professional courses. Therefore, by flipping the classroom design, increasing the student's participation, mobilize the enthusiasm of the students, and enhance the students' learning autonomy.

\section{B. Task design before class}

\section{1) Recording micro lesson video}

Micro-lesson video by "PIP" in the form of recording, PPT production should be simple and clear, not too fancy. Teacher's dress code and PPT background coordination. The appropriate light music is to be made the video more beautiful. Micro class interspersed with simple questions; students only answer questions in order to continue to play the video.

Three problems have set in the micro-lesson video:

1) Motor vehicle third party liability insurance coverage?

2) Motor vehicle third party liability insurance of the liability insurance has?

3) The maximum compensation limit for other vehicles is divided into six grades, respectively, which are six grades?

2) Set up the task list, lets the students learning with the task list.

The content of the task list as follows:

1) The understanding of the specific meaning of the third party liability insurance

2) The understanding of the insurance liability

3) Understand the content of exemption involved

4) Understand the content and amount of insurance compensation and limit

5) Try to using the content of third party liability insurance to analysis of the case in relevant insurance micro lesson

The teacher set up 10 questions on the BB platform, requests the students to finish before class, the teacher correcting, grading, inspection of this part of self-study.

Create QQ, micro-channel group to discuss the thinking questions in the micro lesson. Each student must comment. According to each student discussions to points, join the evaluation to the list. Micro lesson and task lists are provided to the students through the BB platform. 


\section{Task Design during the class}

Class task design is an important link in turning classroom; the design quality is directly related to the success of flipped classroom.

The class design is divided into four links; the concrete content is as follows:

1) The teacher import this lesson: cause you to think, Whether Mr. Lee can get compensation in case? (5 minutes)

Share -- Third party liability Insurance case, the case: " the case of driving a car hitting a family member whether to compensate or not, why?"

2) Inspection and application of Micro video knowledge (30 minutes)

Task one:

What is the meaning of the Third party liability insurance? What is the difference between the Third party liability insurance and other insurance? (10 minutes)

Class activities:

1) Students are divided into small groups to discuss and summarize the meaning of Liability exemption, at the same time, summarizes the differences and relationship between the other types of insurance (each group six to eight students), divided into five groups.

2) Two representatives from each group will present the views of the group and other groups aggregated exchange of views. And then the team numbers will collect the opinions of the exchanged with other groups. Such exchange of three times after the members of each group back to their own group then the group team members integrate the opinion which exchanged with other groups. Finally form their own opinion; the teacher select two teams' spokesman's to report the results to the whole students.

3) Students discussed all views of these two teams together under the guidance of teachers and concluded that the correct meaning of Third party liability insurance and the differences and connections with other insurance.

Task two:

The teacher and students can review the insurance duty and Liability exemption of the Liability exemption which mentioned in the micro-lesson video (10 minutes).

Class activities:

Vies to answer first during the limited time (2 minutes)

The teacher summarizes, and emphases the focus on promoting students' own wrong questions to deepen understanding. (2 minutes)

Task three:

How to analyze the case by using the terms of Third party liability insurance (10 minutes)

Class activities:
1) Group discussing whether to compensate for the case of driving a car hitting the family member.

2) Application group discussion, Guide to group work and inquiry exercises. Each group has a spokesman as a representative to express their opinion. Select two teams to express their opinion, evaluate their opinions, and then add points to the team which gives the correct answer. The spokesman adds 3 points. Every team member adds 1point. Add to the integration table.

3) Expanding the knowledge (5 minutes)

Tasks: which else belong to commercial insurance? What are the insurance liability and liability exemption of these types of insurance?

Classroom activities-discuss the case of the whole car robbery insurance.

1) Task Assignment: How to compensate the whole car robbery insurance? 2) Groups discuss. 3) Vies to answer first. 4) Teacher guide, review and give score.

4) Conclusion (5 minutes)

Class activities:

1) The teacher leads students to summarize the important and difficult Knowledge points of this class.

2) The teacher reviews the performance of each group, and adds points.

Explanation: According to the students' pre-class performance and class performance add points accumulating to the integration table as the part of usual scores and also encouraging students to take an active part in class activities.

\section{Teaching reflection}

(1) The teacher should record micro lesson carefully, make PPT meticulously, design question cleverly to inspire students' learning interest.

(2) The students can study at anytime and anywhere. This approach solves the problem of time and space.

(3) Through discussion, reflection, summarizing and rewarding, the students' learning initiative and participation significantly increased.

(4) The teacher's role has from the leader into the organizer, and the students become the participants. The timeliness of teaching has greatly improved.

\section{CONCLUSIONS}

Combining with teaching practice, the teaching mode of flipped classroom is introduced to the course of Automobile Insurance claim. In the process of teaching, improving the teaching design and a set of the teaching practice mode adapting the vocational college student has been formed. After two semesters of practice teaching, the flipped classroom teaching practice on the Automobile Insurance claim course has shown its advantages. This teaching mode can make student to improve the learning enthusiasm than the traditional teaching. Classroom participation has improved significantly, 
the final test results has increased 30\%. In this paper, the study of flipped classroom in the higher vocational college is of certain reference value for other courses.

\section{REFERENCES}

[1] Lage, M. J., \& Platt,G.J.(2000).Inverting the class-room: A gateway to creating an inclusive learning environment. The Journal of Economic Education,Vol.31, No.1, pp.30-43, 2000.

[2] Strayer, J.F. . The effects of the classroom flip on the learning environment: A comparison of learning activity in a traditional classroom and a flip classroom that used an intelligent tutoring system[D].Columbus: Doctor Degree Thesis of the Ohio State University. (2007)
[3] Talbert, R.(2011). Inverting the linear algebra classroom[EB/OL]. http://prezi.com/dz0rbkpy6tam/inverting-the -linear -algebra-classroom.

[4] Chen Zhenguo, Deng Zhiwen, Yu Guangying. A Study on the Interactions Between Students and Teachers in 'Flipped Classroom' Based on FIAS Analysis Model: A Cast Study of High School Physics Class. Global education, Vol. 43, No 9, pp.65-73, 2014

[5] Jiang Yanling, Xu Tong. Learning Pyramid Theory in the Application and Practice of Flipped lassroom. Instruction and Teacher Professional Development, No.7, pp. 133-138, 2014.

[6] Ma Xiulin, Zhao Guoqing. An Empirical study on the influence of flipped classroom model on information technology course teaching. Journal of distance education. No.1, pp.79-85, 2013.

[7] Chen Fang. Research on the Flippted classroom teaching mode for the foreign trade English correspondence. Journal of AnHui Vocational College Of electronic \& Information Technology. No.2, Vol.14, 2015. 